This is a post-print version of Wyatt, M. (2013). Overcoming low self-efficacy beliefs in teaching English to young learners. International Journal of Qualitative Studies in Education 26 (2), 238-255.

http://www.tandfonline.com/doi/abs/10.1080/09518398.2011.605082

\title{
OVERCOMING LOW SELF-EFFICACY BELIEFS IN TEACHING ENGLISH TO YOUNG LEARNERS
}

\author{
Mark Wyatt \\ University of Portsmouth
}

\begin{abstract}
Drawing on data from observations and interviews, this article presents a case study of one teacher's efforts to overcome low self-efficacy beliefs in teaching English to young learners in a Middle Eastern context. It provides insights into the growth processes involved, highlighting how the teacher drew reflectively upon her experiences to develop deeper practical knowledge and stronger self-efficacy beliefs with regard to the particular task, while supported by a constructivist teacher education programme.
\end{abstract}

Key words: teachers' self-efficacy beliefs, practical knowledge, constructivist teacher education, reflective practice

\section{Introduction}

New challenges can be stressful for teachers. In educational contexts characterized by change, these challenges may include having to adjust to learners of a different age, cognitive level or school culture, or to materials based on unfamiliar learning principles requiring new teaching practices. Currently, there are various international contexts where attempts at government-sponsored innovation are placing such demands on English language teachers (Wedell, 2008).

If teachers are able to adapt successfully to new challenges, certain qualities may be helpful. Desirable attributes in teachers would seem to include reflective qualities, such as flexibility and enthusiasm (Dewey, 1933), reflective skills, such as planning and observing (Ur, 1996), a strong sense of moral responsibility (Ames \& Ames, 1984), positive beliefs as to their own learning potential (Dweck, 2000), well-developed practical knowledge (Elbaz, 1981) and positive task-specific self-efficacy beliefs (Bandura, 1997). For teachers seeking to draw on such attributes, it is also important that teacher education is focused on their needs (Dangel \& Guyton, 2004) and that school contexts are favourable to continuing professional self-development (Borg, 2006). 
In this paper, I consider these various concepts to differing extents in relation to one particular case. My focus is on how a teacher of English in the Middle East on an in-service BA in Teaching English to Speakers of Other Languages (TESOL) struggled to overcome low self-efficacy beliefs in teaching English to young learners (TEYL) when asked to teach a very different age group as a result of curriculum changes. Drawing on qualitative research methods, primarily observations and interviews, I construct a narrative account of her experiences, analysing her development.

The article is structured in the following way. First, I review relevant literature, then focus on the research methodology used and next analyse and discuss the case.

\section{Literature Review}

Teachers' self-efficacy (TSE) beliefs can be defined as their beliefs in their capabilities of supporting learning in various task and context-specific cognitive, metacognitive, affective and social ways (Wyatt, 2010a). These beliefs regarding the fulfilment of specific tasks are important, since "among the types of thoughts that affect action, none [are] more central or pervasive than people's judgements of their capabilities to deal effectively with different realities" (Bandura, 1986, p. 21). In other words, TSE beliefs can have an important influence on the quality and quantity of effort expended on any particular task, as knowledge is transformed into action (Fives, 2003).

Given this central role of TSE beliefs in shaping behaviour, researchers may be interested in how these beliefs develop and how they relate to the following:

- other mediators of effort, such as moral responsibility orientations (Ames \& Ames, 1984);

- other types of teacher beliefs, such as those regarding their own potential to learn and grow on an incremental basis throughout their lives (Dweck, 2000);

- the knowledge possessed by teachers (Fives \& Alexander, 2004), much of which is practical (Calderhead, 1988) and therefore "readily accessible and applicable to coping with real-life situations" (p. 54);

- reflective actions, such as observing while teaching, thinking through a lesson afterwards, conceptualizing and planning ahead (Ur, 1996);

- the stages of development that teachers move through, from novice towards expertise (Berliner, 1988).

However, there is a dearth of research exploring these inter-relationships, notwithstanding one recent case study of a teacher working in a similar context to the teacher reported on here; this focused on the relationship between TSE beliefs and aspects of his practical knowledge (Wyatt, 2010a). There is also a lack of research into the influence of teacher education on TSE beliefs. In one of the very few studies available, Henson (2001) argues that 
teacher education activities that encourage reflective thought can support growth in TSE beliefs, although, in his mixed methods study, he presents only limited qualitative data in support of this.

In examining the processes whereby TSE beliefs develop, quantitative researchers have highlighted the importance of efficacy-building experiences (Tschannen-Moran, Woolfolk-Hoy \& Hoy, 1998). Foremost amongst these experiences, according to Bandura (1997), are 'mastery' experiences (concrete experiences of task performance), as "they provide the most authentic evidence of whether one can muster whatever it takes to succeed" (p. 80). Also influential, according to Bandura, are vicarious experiences (hearing, seeing or reading about others' experiences), verbal persuasion (which may include interactive experiences with others, such as coaching and mentoring) and physiological and affective states (gaining information about efficacy through the senses).

According to Tschannen-Moran et al. (1998), these efficacy-building experiences are subject to cognitive processing (a filtering process whereby some experiences are highlighted in the mind while others are minimized, Labone, 2004). Teachers then assess and perhaps modify their TSE beliefs while analysing the context-specific teaching task in relation to their selfperceptions of competence. These beliefs then influence their behaviour (Tschannen-Moran et al., 1998).

The first part of this explanation, concerning the role of cognitive processing, has been challenged. Fives \& Alexander (2004) argue: "experiences alone do not affect subsequent cognitive processing. Rather, these experiences allow teachers to construct knowledge and belief structures that subsequently influence cognitive processing" (p. 4).

Furthermore, Tschannen-Moran et al.'s (1998) account of how TSE beliefs develop through spiralling cycles has been criticized as unconvincing. Tschannen-Moran et al. claim:

Greater efficacy leads to greater effort and persistence, which leads to better performance, which in turn leads to greater efficacy. The reverse is also true. Lower efficacy leads to less effort and giving up easily, which leads to poorer teaching outcomes, which then produce decreased efficacy (p. 226).

However, as Wheatley (2002) points out, this explanation fails to incorporate the idea "that, at times, doubting one's efficacy might be what helps teachers and teaching the most" (p. 14). Teachers who feel less efficacious in relation to any particular task may be more willing to examine their own practices (Wheatley, 2005). Wheatley's view that doubt, reflection, learning and knowledge growth are intertwined is shared by many teacher educators and represented in learning cycles. In Ur's (1996) cycle of enriched reflection, for example, teachers' growth is depicted through spiralling reflective actions: active experimentation, concrete experience, reflective observation and 
abstract conceptualization, with each of these supported through external input in the form of vicarious and interactive experiences.

Nevertheless, as Wheatley (2005) explains, low TSE beliefs can be damaging if not addressed and if linked to repeated experiences of failure. Outcomes may include disillusionment and withdrawal. A sense of failure can engender an uncomfortable state of cognitive dissonance... [that] can be decreased by largely or entirely avoiding the teaching methods or curriculum content that causes the dissonance... [as well as by] mentally devaluing the importance of the content or the effectiveness of the methods in question (Wheatley, 2002, p. 9).

This underlines the need to understand more about the processes whereby TSE beliefs develop, so that teachers who experience low TSE beliefs can be supported. As we have seen, though, the quantitative research that has led to Tschannen-Moran et al.'s (1998) model is of only limited help in this. Although Bandura (1986) has insisted that "to grant thought causal efficacy is not to invoke a disembodied mental state" (p. 17) and has stressed that reflection is important in helping [teachers] "evaluate and alter their own thinking" (p. 21), quantitative research has neglected the relationships between developing TSE beliefs, reflection (Ur, 1996) and other cognitions, such as practical knowledge (Elbaz, 1981).

Qualitative research, involving the use of narratives centred on teachers' lived experiences, and including their own images and metaphors is required, as in the work of Connelly \& Clandinin (1990). However, while studies of teachers' developing practical knowledge have made use of longitudinal, qualitative case studies since the work of Elbaz (1981), such methodology has been neglected in the field of research into TSE beliefs, as Tschannen-Moran et al. (1998) report. Indeed, only in the last decade have qualitative case studies exploring TSE beliefs started to emerge. Several of these studies have focused on beginning teachers experiencing low TSE beliefs with regards classroom management techniques and instructional strategies. Katie, for example, described by Mulholland \& Wallace (2001), wants to organize her lessons in a learner-centred way, but feels unable to do so; teaching seems like a prison sentence, "doing time" in her words (p. 15). Similarly, Julie, described by Rushton (2004), struggles to deal with problem behaviour; at one point, she is reduced to praying "to help her get through the day" (p. 72).

While Julie gives up teaching (Rushton, 2004), Katie continues, appearing to gain more positive 'mastery' experiences. In their account of Katie's development, Mulholland \& Wallace (2001) provide useful 'thick description' (Geertz, 1973) that allows the reader to function as a co-analyst (Borg, 1997). However, the scope of their interpretation seems limited: they emphasize the role of efficacy-building experiences in Katie's development of stronger TSE beliefs, but do not consider the role of reflection or knowledge growth. Rather, experiences are linked directly to cognitive processing in their 
analysis, after Tschannen-Moran et al. (1998). As Fives \& Alexander (2004) maintain, though, such an explanation for growth in TSE beliefs seems inadequate, as it disregards the role of other cognitions. Qualitative investigations that take an exploratory, and so an emic rather than an etic approach (Cohen, Manion \& Morrison, 2007), may be required to trace the processes of developing TSE beliefs and the relationship between these processes and other aspects of teachers' cognitive growth; e.g.; in practical knowledge.

However, as already indicated, there is a lack of such studies, although others do highlight the role of the context in shaping TSE beliefs (e.g.; Milner \& Woolfolk-Hoy, 2003). Various researchers (e.g. Pajares, 1997; Henson, 2002) agree that in-depth qualitative research, offering thick description and triangulation, e.g.; of interview and observational data, is needed to shed light on developmental processes.

I use such research methodology, below, in exploring how a teacher of English in the Middle East, asked to teach younger learners as a result of curriculum changes, struggled to overcome low TSE beliefs. Her situation was not uncommon; increasing numbers of children around the world are starting to learn English at increasingly younger ages (Cameron, 2003), one consequence of which is the re-assigning, and sometimes re-training, of English teachers to meet this demand. Teachers so re-assigned might face challenges in some ways similar to those experienced by beginning teachers while they are adjusting to the new situation, challenges such as providing appropriate instructional strategies and classroom management techniques while fostering student engagement (Tschannen-Moran \& Woolfolk-Hoy, 2007). These challenges might influence their TSE beliefs. I now describe the context.

\section{The research context}

The teacher participating in this research was studying for a BA TESOL run by the University of Leeds for the Ministry of Education in the Sultanate of Oman. This was an in-service course, designed both to upgrade the qualifications of Diploma-holding teachers, many of whom already had a decade's teaching experience, and to help them contribute to curriculum renewal. Some had positions of responsibility: they were already Senior English Teachers in their schools.

The programme offered various modules covering English language teaching methodology, language analysis, and research methods. It exposed participants to communicative language teaching (Richards, 2005), which was new to many of them. It was also 'constructivist' (Dangel \& Guyton, 2004) in various ways, e.g. in incorporating awareness-raising activities that invited teachers to re-examine their beliefs and practices, and in encouraging them to engage in problem-solving, action research, the adaptation and evaluation of 
materials, and reflection. Reflective processes were frequently modelled by tutors, such as myself; this modelling emphasized the need to embrace doubt as part of the reflective process and to be tolerant of ambiguity, on the basis that so much in classroom decision-making 'depends' on contextual factors.

The teachers attended summer and winter schools intensively and then studied part-time throughout the school year, attending day release classes once a week. As the regional tutor of one cohort of 35 teachers, I worked with them intensively throughout their three-year course, providing lectures and seminars, offering tutorials, conducting observations in their schools and giving feedback. I observed each teacher once a semester, observations which were not assessed. The focus of the post-lesson discussions was on supporting reflection and learning (for more details of the BA TESOL, see Atkins, Lamb \& Wedell, 2009).

The BA programme was part of a large-scale educational reform project focused on curriculum renewal linked to a building programme of 'Basic Education' schools. These schools, equipped with air-conditioned classrooms containing electronic equipment and whiteboards, gradually replaced 'General Education' schools, which can be characterized by chalk on blackboards and desks in rows. Under the new system, classes are smaller and children sit in groups. They also start learning English from Grade 1, rather than from Grade 4, as previously.

To speed up the curriculum renewal process, in September 2004 all Grade 1 children throughout the Sultanate, including those in General Education schools, were introduced to the new curriculum, 'English for $\mathrm{Me}^{\prime}$. Some teachers, including the one in this study, had already taken short in-service courses preparing them for this change.

\section{Research methodology}

My research questions are as follows:

1. To what extent did a teacher of English overcome low teachers' selfefficacy beliefs in teaching English to young learners?

2. What factors might explain the development of her teachers' selfefficacy beliefs?

This focus developed when I realized that a teacher, Sarah (pseudonym used), I was researching as part of a larger-scale study (Wyatt, 2008) was experiencing low TSE beliefs when confronted by a new challenge (teaching Grade 1 after a decade teaching Grades 7-9) and adjusting to children of a different cognitive level and to new teaching practices. For, unlike the curriculum being phased out, 'English for Me' emphasises the development of receptive skills in a stress-free environment. Children are encouraged to play with the language and learn by doing. The syllabus includes Total Physical Response (TPR) activities, action songs and rhymes, games and craftwork. 
Such activities need space and resources, which, in Sarah's General Education school, were limited.

Nevertheless, I hypothesized that after initial uncertainty Sarah could meet these challenges successfully and develop stronger TSE beliefs. She was already well-established in her teaching context as Senior English Teacher and had positive relationships with colleagues and headmistress. She was also a high performing student on the BA TESOL (she was on track for and later gained a 2:1). I hypothesized that reflective qualities she demonstrated in her studies and her work with older learners that I have discussed elsewhere (Wyatt, 2009), qualities which included those identified by Dewey (1933) as key to reflective practice - enthusiasm, flexibility and a sense of responsibility, would help her overcome challenges in her work with younger learners.

Sarah had been selected for the larger-scale study (Wyatt, 2008) through a process of 'purposive' and 'theoretical' sampling (Silverman, 2000, discusses using these procedures). Regarding purposive sampling, a key criterion she met, one highlighted by Stake (1995), related to the opportunities she provided for me to learn from her. Whenever I visited Sarah's school, she was open and welcoming, and was always prepared to talk at length about her work. Regarding theoretical sampling, this was influenced by the following views: reflective practice can help teachers develop (Ur, 1996); mentoring can support this process (Malderez \& Bodóczky, 1999); as an educational innovation encouraging reflection and including mentoring, the BA programme might support changes in cognitions and teaching practices. Sarah was included in a sample selected from amongst volunteers, partly because she seemed both reflective and focused on personal change from the outset, e.g.; in enthusing about communicative teaching methodology she was using with teenagers for the first time (Wyatt, 2009).

In conducting the research I was an insider, committed to supporting Sarah's development. As her regional tutor, I tried to help her realize the aims of the BA TESOL course, and so benefit from it both academically and practically. Sarah was a volunteer who signed an informed consent form, which promised anonymity and the right to withdraw at any time. Ongoing consent was requested each time I wished to observe or interview. The research was conducted according to strict ethical guidelines.

The main research methods were observations and interviews; a combination recommended in teacher cognition research (Borg, 2006). While the observations provided direct evidence of Sarah's classroom behaviour, the interviews were semi-structured (Kvale, 1996) and provided opportunities for her to reflect upon her teaching, and express her own feelings and beliefs; these interviews were thus central in providing access to her cognitions, including her task-specific TSE beliefs. As argued (in 2) above, such a 
triangulation of qualitative methods is required to provide insights into the processes of developing TSE beliefs.

There were five observations (of which I kept a narrative record that was supplemented during post-lesson discussions and typed up afterwards) and seven semi-structured interviews (audio-recorded and transcribed) throughout the research period of three years. I also drew upon conversations with Sarah in producing field notes and analysed assignments she produced as part of the BA course for evidence of changing ideas.

In analysing data, I have sought to be reflexive at every stage in questioning my interpretations, as grounded theory emerged from interactive and iterative analytical procedures (Calderhead \& Shorrock, 1997). So, analysis commenced during the data collection phase, which allowed successive interviews to be shaped by previous ones, as I sought to check my interpretations. After each data-gathering opportunity, I would transcribe interviews and type up observations shortly afterwards. Categories were gradually developed in which extracts of data were grouped, sequenced and juxtaposed for further questioning, and I drew diagrams, developing my own conceptual models to explain change processes. In constructing Sarah's story, refracted through my own experience, I have drawn upon her own words and images in seeking to achieve narrative unity (Connelly, Clandinin \& He, 1987). I have used 'thick description' (Geertz, 1973), aiming to provide the reader with a clear and vivid understanding of the case.

In this particular article, I am presenting a case study within a case study. While I studied various aspects of Sarah's development over three years, including her use of communicative tasks with teenagers (Wyatt, 2008, 2009, 2010b; Wyatt \& Borg, 2011), the main action in this particular story of overcoming low TSE beliefs occupied a one-year segment of that time, when Sarah needed to adjust to teaching younger learners. Most central to this story are the narrative records of two observations (one year apart) and the semistructured interviews that followed immediately afterwards. Sources of data are coded as follows (after Borg, 1998):

\begin{tabular}{|l|l|l|}
\hline Teacher's pseudonym & Source of data & Number \\
\hline Sarah $-\mathrm{S}$ & Assignment - A & $1-7$ \\
& Interview - I \\
& (Field) Notes - N \\
& Observation - O & \\
\hline
\end{tabular}

So SI.7 is the seventh interview I conducted with Sarah, SO.5 the fifth observation of her teaching, SA.1 her first assignment. SN.1 refers to field notes. 


\section{Findings}

I organize this section in two parts, first analysing (in 5.1) Sarah's TSE beliefs when she was new to teaching younger learners, and then (in 5.2) her TSE beliefs a year later, when she was more efficacious.

\subsection{Sarah's first experiences of teaching Grade 1 and low TSE beliefs}

In September 2004, more than a decade into her teaching career and halfway through the BA TESOL, Sarah was asked to teach Grade 1. She highlighted contextual challenges in relation to this new task. Classrooms in her General Education school were not designated especially for English and there were no English posters on the walls. Nor did the classrooms contain lockable cupboards, so equipment had to be carried around. Space for TPR and mingling activities was restricted (SI.4).

Despite these challenges, Sarah had been partially prepared for the career change of switching to Grade 1 . Five years earlier, she had attended a short inservice course focused on the new curriculum. Then, an early BA module gave her "new ideas about how children learn" (SI.2). She claimed, in her first assignment, children have an instinct for meaning, a desire to communicate, and learn if they have a real purpose. They need meaningful topics and varied activities that appeal to their sense of fun (Halliwell, 1992) (SA.1). However, at this stage she had no experience of teaching very young learners.

The initial experience of teaching Grade 1 came as a shock. Sarah's dilemma concerned catering to young learners' instincts, while establishing sufficient order to run a lesson smoothly: "I wanted to be kind to them, but at the same time I wanted to control the class and I felt that if I became too kind then I would lose control" (SI.7). Sarah found the children's behaviour unpredictable and was uncertain how to act (SI.4). She initially doubted her ability to achieve an appropriate balance. "Am I the right teacher for this?" she asked me, a week into the semester (September 2004) (SN.1). She later reported feeling constantly worried about her work (SI.4).

Her low TSE beliefs surprised me initially, as I knew Sarah to be a selfconfident teacher of teenagers, an understanding I checked:

Interviewer: Did you feel like that when you were teaching Grade 9? Sarah: No I felt relaxed really, because I have a good idea about that coursebook. I know everything in that coursebook so I am not worried. I know what will happen during this task, what are the difficulties that they will face and how I will solve the problem, but because this [teaching Grade 1] is new for me, that's why I am so worried and I am always busy because of this thinking (SI.4).

So, Sarah's higher TSE beliefs with Grade 9 were not immediately transferable. Feeling empowered by the BA course (SI.1), she was able to adapt the Grade 9 syllabus in various ways; e.g. by adding a communicative task or groupwork or by using the materials in a different way. She reported: 
when I do something new for them, I am not sure about the result but I know that this is something new, so maybe the children will like it because they did it in another way; maybe this is a new way and they will like it and maybe they will succeed. I am thinking like this (SI.4).

Clearly, Sarah was more efficacious in her work with teenagers, approaching teaching tasks, even new ones, anticipating success. The contrast in her feelings in teaching different age groups in the same large school illustrates how task- and domain-specific TSE beliefs are.

Approaching lessons with Grade 1, she suffered from continual anxiety: I feel worried everyday when I enter my class. I feel worried. I am thinking about what I am going to do in that step. Are they going to do it well or not? I am a little negative about myself. I' $m$ always thinking, for example, [about] the step where they're pointing, you know; before I sleep, I am thinking: Are they going to point or not? Is it the right way to do it like that or they should hold the card up or what? (SI.4).

In Bandura's (1997) model, this type of anxiety, involving sleep loss, relates to negative efficacy information provided to the teacher by her physiological and affective state. Sarah's low TSE beliefs regarding classroom management and instructional strategies seem to have been caused by feelings of inadequacy.

Yet, there were signs that she could actually handle the task. In October 2004, I observed Sarah teach a Grade 1 class (when she had about six weeks' experience of this age group). The lesson was the seventh of ten in a unit on colours, and seemed to go quite well. Sarah did appear slightly nervous when a big book page she fixed to the whiteboard at the start fell down immediately. And at the beginning, when she tried to elicit colours from the class, she perhaps gave in too quickly and started telling (SO.3).

Afterwards, though, she did manage to elicit. The children next pointed to colour cards as they listened to a song about the rainbow. The song was repeated, and they had to listen and point and say. Sarah gave clear instructions and monitored carefully. Next, she elicited objects, such as 'pencil', 'chair', 'book' from flashcards; inviting answers from amongst a sea of raised hands. I noted at the time that a peer check before this whole class check would have provided more of the children with an opportunity to speak (SO.3).

Next, Sarah made use of realia (brought from home to extend the activity) in eliciting sentences: "It's a green book"; “It's a blue bag”. There was more listening and pointing; listening, repeating and pointing; and when the listening was over Sarah asked: "Who would like a star?" She distributed stars (which perhaps would have been more appropriate as a reward later) to students who had performed well in the listening and then focused again on 
the big book page affixed to the whiteboard; eliciting to check. "It's a teddy bear blue", one girl said, before another offered the expected word order. After this focus on form, the instruction was: "now discuss with your group" and the children practised with pictures on a page in their course books (which was identical to the big book page on the whiteboard) (SO.3).

From my perspective as an observer, the learning outcomes seemed largely achieved. This should have been a source of growth. As Bandura (1986) argues, if a teacher is to develop task-specific self-efficacy beliefs, practical 'mastery' experiences of actually succeeding in similar tasks are invaluable. However, it is also important that any experiences of success are consciously reflected upon (Bandura, 1997), together with other aspects of the experience that contribute to learning (Wheatley, 2002), for without deliberative reflection, growth in teaching is likely to be limited (Ur, 1996).

Sarah reported reflecting on her Grade 1 lessons. She taught three Grade 1 classes each day (thus teaching the same material to three groups) and often made adjustments after the first. After the lesson described above, she told me:

there are many things in my mind I have to think about, especially with the first class... so I faced, for example, many problems there, so next time in another class I have to avoid these problems and I reflect on them and try to solve the problems. I don't have somebody in the school to talk to about this but I try to use my imagination and think how if I do it like this or like that... and really it succeeds (SI.4).

So, by reflecting and learning from experiences that challenged her, Sarah was able to develop strategies that led to more successful outcomes and thus gain positive 'mastery' experiences. Reflection, and the doubt that would drive this, was key to changes in her TSE beliefs in TEYL even within the same day, though worries would then reappear regarding the next day's teaching. Again this illustrates how specific TSE beliefs are to any particular task (in this case, a day's lesson) in any particular context.

As well as practical 'mastery' experiences of succeeding, interactive experiences with peers and advisors can also influence TSE beliefs, as Bandura (1997) argues. As well as reflecting deeply, Sarah sought out feedback on her teaching. In September 2004, soon after she started teaching Grade 1, her Ministry of Education supervisor visited:

She came for the first time to my school and she said she didn't want to enter classes; she only came to see us, but I told her: "please I want you to see me in Grade 1 because I am not sure about my teaching"; so I took her - she didn't want to enter my class - I said: "please" and then she came inside and she sat. I taught my lesson and she gave me some useful pointers about how to manage the class and about groupwork (SI.4). 
So Sarah gained an interactive learning experience she considered useful, her proactive behaviour prompted perhaps by a combination of the following: a determination to fulfil her sense of moral responsibility (Ames \& Ames, 1984), positive reflective attitudes (Dewey, 1933) and beneficial self-efficacy doubts (Wheatley, 2002). Also crucial to this motivated behaviour was the incremental view she appears to have held of her own learning potential (Dweck, 2000); Sarah believed she could develop, stimulated by the advice she received.

Interactive learning experiences in her context were limited, though. Sarah regretted that, as the first teacher in her school to teach Grade 1, she had noone to consult on a daily basis. She also regarded it as a limitation that she didn't "know the people who designed the teachers' book [produced in Oman], how they are thinking" (SI.4).

Yet, every week Sarah met fellow BA students, some from Basic Education schools, and elicited their opinions, demonstrating through this behaviour positive self-beliefs (Dweck, 2000), and willingness to both reflect (Dewey, 1933) and embrace doubt (Wheatley, 2002). On consulting other teachers, she obtained varying and sometimes contradictory views, which prompted her to question further, engaging in 'abstract conceptualization' as Ur (1996) describes this. One colleague, for example, suggested that if she gave instructions in Arabic first and then in English, this would help her manage the class, which troubled Sarah, as it contradicted research into language acquisition she had read. She checked her understanding with me: "Don't the children need to listen to the instructions in English", she asked, "if they are to pick them up?" I agreed, suggesting she used gestures to support short instructions in English. She said she would do this, using L1 (the first language) as a back-up (SN.1). She felt this type of mentoring helped (SI.4).

In October 2004, I was concerned for Sarah's TSE beliefs. However, there were positive signs: in her willingness to accept self-efficacy doubts while believing she could grow, in her engagement in reflective actions, in the thoughtful way she made use of efficacy-building experiences. In short, she possessed qualities that I felt should help her develop stronger TSE beliefs in teaching young learners.

\subsection{A year later and more developed TSE beliefs}

I visited Sarah's school again the following year, in October 2005, and observed her teach another Grade 1 lesson. This was actually on the same topic, colours, as in the previous year, but was earlier in the unit (the fifth of ten lessons). In 2004/5, Sarah had switched to Grade 9 in the second semester, so had only taught Grade 1 between September and December. She had therefore gained some but not a great deal more experience of teaching very young learners. Sarah was nevertheless more efficacious:

Interviewer: you were quite worried about it, I remember, last year 
Sarah: Last year yes, but this year no, it's different. I know it's a little experience but really I feel more relaxed, more active, I feel more confident about teaching Grade 1, and that time, as I told you last year, I was worried about how to control these students but now they are ok and I feel I can control them (SI.7).

Sarah's earlier concerns had been with classroom management techniques and instructional strategies. However, the sense of anxiety she had experienced the year before had "disappeared completely" (SI.7). She had thus overcome low TSE beliefs in these areas.

The focus of the October 2005 post-lesson discussion was much more on children's needs, which might be an indicator of Sarah's developing expertise. Berliner (1988) suggests that greater security in classroom management enables teachers to concentrate more fully on learning outcomes. Focused on the learners, Sarah reported that she could now adapt the course material for Grade 1 as she saw fit:

last time I taught every page in that teachers' book, I did every part as it is and I feel it is... I mean I know my pupils, I know the level of my students, I know what is suitable for them, so this time I tried to adapt, I tried to change things according to their levels, to their age, I mean there are many complex ideas in that book... we have some games which are not culturally appropriate for these children, they don't have this in Oman at all and if you teach them this kind of game in Arabic they will not be able to do it, so how will it be if you teach them [this] in English? It's very difficult for them (SI.7).

Sarah's TSE beliefs in adapting course material for her learners seemed to develop through the BA course. Though she taught Grade 1 for the first time 'by the book' in 2004, she was already experimenting with higher grades (5.1, above), adapting Grade 9 lessons to add communicative tasks. Prior to the BA course, she had been unable to do this, despite a decade teaching these grades. In 2003, she told me:

Before I didn't have any idea about how to create a context, any context, how to make it clear, how to start the unit ... I used the teachers' book as it is, I didn't change anything, but now I am studying on the BA, I really try to use what I have learned in my teaching (SI.1).

By 2005, after a great deal of experience on the BA programme of adapting materials for learners for a variety of modules, she had developed practical knowledge and TSE beliefs in this area:

When I plan, I can see which part, which step, is suitable for them, which part might be difficult and how I am going to adapt it or create something new ... of course you can't do it at once like magic and suddenly it will be perfect. It requires hard work and concentration. The process of analysing and reviewing needs a clear mind, but I have a lot of ideas now (SI.7).

So, this self-report data suggest that Sarah developed practical knowledge and TSE beliefs in adapting materials for Grade 9 first. It seems she was able 
to draw upon this growing expertise in her work with Grade 1 after low TSE beliefs in classroom management techniques and instructional strategies had disappeared. In the October 2004 interview, her focus of attention was on herself and her teaching methods (SI.4); a year later, it was on the learners and their needs (SI.7). Self-report data taken on its own can be questionable, though (Borg, 2006), and I now turn to observational data from the October 2005 lesson for triangulation.

Was there evidence in this lesson of growing practical knowledge and more positive TSE beliefs in Sarah's teaching of Grade 1? The focus was on helping the children learn colours and there were TPR activities that involved listening and kinaesthetic movement, and speaking activities that supported the development of vocabulary knowledge; words such as 'purple', 'orange' and 'pink' were retrieved and produced. Much use was made of groupwork (SO.5).

Regarding Sarah's management of the class, I noticed she gave very clear instructions; always in English first (as in the previous lesson), often supported by gesture and sometimes by a few words of L1; and she provided plenty of encouragement while monitoring (more so than in the previous lesson). "Very good, yes", she said, as she walked around the classroom; "excellent, this girl is excellent". Sarah signalled the beginning and end of activities very clearly; e.g.; on one occasion, saying: "Stop now... if you didn't finish, do so at home" (and then, after a pause) "now, take your chairs and face the board". The children did pay attention, and transitions between the activities were orderly. They were also allowed to be children, clearly enjoying the TPR activities; furthermore, they were able to gain peer support. At one point, for example, while Sarah was busy with a group at the front near the door, two girls at the table to my left were helping their friend. "Red, red" they were saying, as their friend held up an orange card. The positive atmosphere in the classroom seemed conducive to learning (SO.5).

Sarah appeared much more comfortable with the teaching methodology she was using and issues she had been worried about a year earlier, such as maintaining sufficient control while being 'kind', appear to have been resolved. In short, her lesson seemed efficaciously managed, while focused on clear learning outcomes (SO.5).

After the lesson, Sarah identified changes in her classroom management. These included closer monitoring and greater encouragement, a reflection which tallies with my observation notes (SO.3, SO.5). She had also established rules at the start of this academic year to cover what happened between one activity and another:

I told them in Arabic at the beginning... I know they are young but though they are young, I think they can still understand, and if you tell them: "if you want to learn English, you should listen carefully..." This was at the beginning, so between the activities I told them, for example: "stop, please" 
and "stop" means that they stop moving, they should listen, focus and look at the teacher or at the board, because there is something new that will be introduced (SI.7).

These instructions had had the desired effect, calm during a transition. "I can see they're listening," Sarah reported, "and they are focusing". It was not like this in other Grade 1 lessons. "When I am speaking with other subject teachers", Sarah reported; "they told me they're very noisy they're not sitting at all" (SI.7). The technique she used seemed to work in her lesson, providing positive experiences to strengthen her TSE beliefs in classroom management. Sarah shared this technique with others (SI.7).

Sarah offered further evidence she was comfortable with the new teaching methodology. She speculated that another reason why the children behaved well was that

maybe also they like the subject, it's interesting, something new, and also because of the songs, we use a lot of songs and we dance in the lesson and I jump with them and play with them and maybe this is also one reason (SI.7).

So there is observational and interview data that Sarah's more developed TSE beliefs were based on a firmer foundation of practical knowledge. Sarah had used her experience of teaching Grade 1 to develop classroom management strategies that allowed her to achieve a balance in her teaching; no longer worried about control, she was able to focus on the young learners' needs. Of course, the situation was still far from perfect. Sarah was conscious of contextual challenges, such as large class size and the school's broken photocopier. Nevertheless, she reported she felt "happy": "I am not worried like last year... that particular experience made me conscious of many things" (SI.7).

\subsection{Summary}

In the sections above, I have first explored Sarah's low TSE beliefs in October 2004, examining her experiences, cognitions and behaviour as she tried to resolve her problems (5.1). I have then presented evidence of more developed TSE beliefs a year later. Using observational and interview data, I have explored these beliefs in relation to growing practical knowledge (5.2). I now address my research questions.

\section{Discussion}

\subsection{To what extent did Sarah overcome low teachers' self-efficacy beliefs in} teaching English to young learners?

It is evident that Sarah did overcome low TSE beliefs. A year after she first taught Grade 1, she reported feeling more efficacious in being able to manage the class, which allowed her to focus on achieving learning outcomes, and adapt course material. Though the context imposed certain challenges she remained conscious of, by 2005 Sarah felt she had developed the strategies required for her to manage a Grade 1 class in her context successfully, and 
was able to articulate these (SI.7). Observational evidence supports interview data: There was evidence in the 2005 lesson of greater composure and improved strategies to support classroom management, relating to Sarah's monitoring, encouragement, signalling of transitions between activities and use of interactive groupwork (SO.3, SO.5).

\subsection{What factors might explain the development of her teachers' self-efficacy beliefs?}

Various factors have been highlighted that might account for Sarah's development of more positive TSE beliefs, and I attempt a 'merging of fields', as called for by Wheatley (2005), in drawing on several research traditions in my analysis of the changes that took place. Firstly, from the perspective of educational psychology, Sarah believed she had the capacity to develop, which Dweck (2000) argues is vital if growth is to occur. Since Sarah held such an 'incremental' view of her own learning potential, she was able to benefit from doubting her self-efficacy (Wheatley, 2002). As Wheatley (2005) maintains, these doubts can foster change, reflection and collaboration, and support motivation to learn. Evidence of Sarah reflecting, collaborating and trying to change, prompted by self-doubt, has been presented above. From a psychological perspective, too, Sarah was motivated by her sense of moral responsibility towards the learners (Ames \& Ames, 1984) and had positive attitudes towards reflection (Dewey, 1933).

My second perspective is from research into teacher cognition. The growth of Sarah's TSE beliefs in teaching young learners seems inextricably linked to developments in her practical knowledge in the same area. As indicated above (in 2), practical knowledge has both experiential and performative dimensions; much of what teachers know "originates in practice and is used to make sense of and deal with practical problems" (Borg, 2006, p. 13).

Evidence from both interview and observational data presented (in 5.2) above demonstrates growth in Sarah's practical knowledge with regards classroom management techniques; this growth appears to have been crucial for the development of more positive TSE beliefs.

This finding is resonant, since links between practical knowledge growth and the development of TSE beliefs have not been attended to by quantitative researchers approaching the study of TSE beliefs from the perspective of educational psychology. On the contrary, 'cognitive processing', a filtering mechanism, (Labone, 2004), has been used by these researchers to explain changes in TSE beliefs (2, above). As a consequence of this interpretation, teachers" knowledge and skills are "powerful, uncontrolled lurking variables in the midst of virtually all [of these researchers'] data" (Wheatley, 2005, p. 9). However, despite criticism of Tschannen-Moran et al.'s (1998) model which has focused on its neglect of knowledge growth (Fives \& Alexander, 2004), prior to the current study and a related one (Wyatt, 2010a), I am unaware of any empirical evidence that has been presented to support the idea that 
practical knowledge growth is intimately linked to the development of more positive TSE beliefs.

My third perspective is from teacher education and the view that reflection is crucial to teacher development. Evidence has been presented above that Sarah engaged in reflective actions (Ur, 1996), such as planning, thinking over lessons with a view to making changes for the next class and conceptualizing problems in a more abstract way. Reflective processes were encouraged on the teacher education course through modelling, action research assignments that required teachers to reflect on innovations, and mentoring ( 3 , above). I have argued elsewhere, in providing an in-depth case study of another teacher who was on the same course (Wyatt, 2010c), that such support may have helped teachers develop as reflective practitioners. I have not focused in this paper on Sarah's development in this way, but have presented evidence that she engaged in reflection and that this helped her develop both practical knowledge in TEYL and more positive TSE beliefs.

This finding is resonant since, while reflection on experience has been acknowledged as crucial by Bandura (1997), researchers influenced by Tschannen-Moran et al. (1998), such as Mulholland \& Wallace (2001), have tended to ignore the role of reflection in their analysis of how TSE beliefs grow (2, above). Indeed, Wheatley's (2002) work in highlighting the role of self-efficacy doubts in stimulating reflection and change has recently been described as 'a puzzle' by the quantitative researchers, Tschannen-Moran \& Johnson (2010). Qualitative data is needed to explore the role of reflection in supporting the development of TSE beliefs, and again, I believe the current study may be the first to offer this explicitly.

To summarize, various factors, interacting in complex ways, appear to have influenced the development of Sarah's TSE beliefs in TEYL. Tschannen-Moran et al.'s (1998) model seems unable to explain the development that took place. However, by merging fields, as called for by Wheatley (2005), and drawing on research into teacher cognition and teacher education, I believe I have provided a fuller picture.

\subsection{Conclusions}

\section{Conclusions and recommendations}

The following conclusions need to be set against research limitations, which relate chiefly to the quantity of the observational data; my work schedule did not allow more frequent observations. However, I was reflexive in subjecting those available to detailed study, and triangulated this analysis with analysis of field notes and interviews (4, above).

Sarah's success in overcoming low TSE beliefs can be partly explained by various psychological and cognitive factors, including her self-beliefs about her ability to grow, her self-doubts and reflective qualities; these helped her to 
engage in reflective actions. The context of the school also helped, in providing efficacy-building experiences, particularly 'mastery' experiences, while constructivist elements of the BA TESOL, including mentoring, supported growth in practical knowledge. Once she had developed routines that supported her in managing her Grade 1 class, she could focus more on the needs of the learners, drawing on her experience of adapting materials for teenagers. Sleeplessness and negative feelings of inadequacy, both of which relate to low TSE beliefs, had disappeared. While she remained realistic about challenges in her particular context, Sarah had developed positive TSE beliefs.

\subsection{Implications}

Various implications emerge from this study. Firstly, Sarah's experiences demonstrate that TSE beliefs can be fragile in in-service, as well as pre-service teachers. This underlines teachers' need for workplace-based pedagogical and psychological support when undertaking new tasks. Curriculum planners have a responsibility to provide such support. Sarah gained some help from her Ministry of Education supervisor, but may have benefited from further mentoring in her school or a local cluster of schools (e.g.; as recommended by Malderez \& Bodóczky, 1999).

Secondly, Sarah was fortunate in being able to repeat the same lesson material with different classes each day, so gaining efficacy-building experiences (Bandura, 1997). If timetables are organized in ways that help teachers engage in reflective actions, with time to reflect and re-plan either side of concrete teaching experiences (Ur, 1996), then growth in TSE beliefs can be supported. In timetabling, schools could show such sensitivity to teachers' needs.

Thirdly, Sarah was fortunate in that, while adjusting to Grade 1, she was also taking a part-time in-service BA TESOL that had constructivist features (Dangel \& Guyton, 2004). The course empowered her in various ways; e.g.; in helping her access public theory she could draw upon in her conceptualizations, in providing her with the tools to analyse and adapt course material, in helping her observe her own practice, in modelling reflective processes. Sarah developed practical knowledge while engaged on this course, as did others in the same multi-case study (Wyatt, 2010a, 2010b, 2010c, 2011; Wyatt \& Borg, 2011). If teacher education is centred on constructivist principles, it can lead to "the flowering of empowered teachers" (Wideen, Mayer-Smith, \& Moon, 1998, p. 159). This suggests that more teacher education courses should be based on such principles.

Finally, there are implications regarding research methodology. In this paper, I have highlighted inadequacies in Tschannen-Moran et al.'s (1998) model of how TSE beliefs develop, focusing primarily on their notion that, through cognitive processing (but not knowledge growth?), more positive TSE beliefs lead to better performance and success in spiralling cycles (uninfluenced by reflection and self-doubt?). This remains the dominant view presented by 
quantitative researchers of TSE beliefs (e.g. Tschannen-Moran \& Johnson, 2010); it should be challenged. Qualitative case studies are required that take an emic approach and embrace a merging of fields (Wheatley, 2005). Studies that triangulate interview and observational data and make use of 'thick description' in the piecing together of teachers' narratives to make sense of their experiences are needed.

Further research in this area could target in-service teachers whose TSE beliefs might be vulnerable. These might include teachers of children with special educational needs (Henson, 2001), and language teachers, given the various challenges they face (Chambers, 1999). Such teachers include non-native speaker teachers of English, a group whose cognitions are under-researched (Hayes, 2005).

\section{References}

Ames, C. \& Ames, R. (1984). Systems of student and teacher motivation: Towards a qualitative definition. Journal of Educational Psychology 76 (4), 535-556.

Atkins, J., Lamb, M. \& Wedell, M. (2009). (Eds.). International collaboration for educational change: The BA project. Muscat: Ministry of Education, Sultanate of Oman.

Bandura, A. (1986). Social foundations of thought and action: A social cognitive theory. New York: Prentice-Hall. Retrieved 23 November 2003 from Emory University website: www.emory.edu/EDUCATION/mfp/effpassages

Bandura, A. (1997). Self-efficacy: The exercise of control. New York: Freeman.

Berliner, D.C. (1988). The development of expertise in pedagogy. Washington: AACTE Publications.

Borg, S. (1997). Writing up qualitative research. Research News (IATEFL Research SIG Newsletter) 10, 1-8.

Borg, S. (1998). Teachers' pedagogical systems and grammar teaching: A qualitative study. TESOL Quarterly 31 (1), 9-38.

Borg, S. (2006). Teacher cognition and language education: Research and practice. London: Continuum.

Calderhead, J. (1988). The development of knowledge structures in learning to teach. In J. Calderhead (Ed.), Teachers' professional learning (pp. 51-64). London: The Falmer Press.

Calderhead, J. \& Shorrock, S. (1997). Understanding teacher education: case studies in the professional development of beginning teachers. London: Falmer.

Cameron, L. (2003). Challenges for ELT from the expansion in teaching children. ELT Journal 57 (2), 105-112.

Chambers, G.N. (1999). Motivating language learners. Clevedon, UK: Multilingual Matters.

Cohen, L., Manion, L. \& Morrison, K. (2007). Research methods in education (6 ${ }^{\text {th }}$ ed.). London: RoutledgeFalmer. 
Connelly, M.F., Clandinin, J.D. \& He, F.M. (1997). Teachers' personal practical knowledge on the professional knowledge landscape. Teaching and Teacher Education 13 (7), 665-674.

Connelly, M.F. \& Clandinin, J.D. (1990). Stories of experience and narrative inquiry. Educational Researcher 19 (5), 2-14.

Dangel, J.R. \& Guyton, E. (2004). An emerging picture of constructivist teacher education. The constructivist 15 (1), 1-35.

Dewey, J. (1933). How we think. Boston: D.C. Heath.

Dweck, C.S. (2000). Self-theories: Their role in motivation, personality and development. Philadelphia: Taylor \& Francis.

Elbaz, F. (1981). The teacher's 'practical knowledge': A report of a case study. Curriculum Inquiry 11, 43-71.

Fives, H. (2003). What is teacher efficacy and how does it relate to teachers' knowledge? Paper presented at the American Educational Research Association Annual Conference, Chicago. Retrieved 28 January 2007 from the website: www6.tltc.ttu.edu/hfives/Fives.AERA2003

Fives, H. \& Alexander, P.A. (2004). Modelling teachers' efficacy, knowledge, and pedagogical beliefs. Paper presented at the annual meeting of the American Psychological Association, Honolulu. Retrieved 28 January 2007 from the website: www6.tltc.ttu.edu/hfives/Fives\&Alexander.APA

Geertz, C. (1973). The interpretation of cultures: Selected essays. New York: Basic Books.

Halliwell, S. (1992). Teaching English in the primary classroom. Harlow, UK: Longman.

Hayes, D. (2005). Exploring the lives of non-native speaking English educators in Sri Lanka. Teachers and Teaching: theory and practice 11 (2), 169-194.

Henson, R.K. (2001). The effects of participation in teacher research on teacher efficacy. Teaching and Teacher Education 17 (7), 819-836.

Henson, R.K. (2002). From adolescent angst to adulthood: Substantive implications and measurement dilemmas in the development of teacher efficacy research. Educational Psychologist 37 (3), 137-150.

Kvale, S. (1996). InterViews: An introduction to qualitative research interviewing. Thousand Oaks, California: Sage.

Labone, E. (2004). Teacher efficacy: maturing the construct through research in alternative paradigms. Teaching and Teacher Education 20 (4), 341-359.

Malderez, A. \& Bodóczky, C. (1999). Mentor courses: A resource book for trainertrainers. Cambridge: CUP.

Milner, H.R. \& Woolfolk-Hoy, A. (2003). A case study of an African American teacher's self-efficacy, stereotype threat, and persistence. Teaching and Teacher Education 19 (2), 263-276.

Mulholland, J. \& Wallace, J. (2001). Teacher induction and elementary science teaching: enhancing self-efficacy. Teaching and Teacher Education 17 (2), 243-261. 
Pajares, F.M. (1997). Current directions in self-efficacy research. In M. Maehr and P.R. Pintrich (Eds.), Advances in motivation and achievement 10, 1-49. Greenwich: JAI.

Richards, J.C. (2005). Communicative language teaching today. Cambridge: CUP. Rushton, S.P. (2004). Using narrative enquiry to understand a student-teacher's practical knowledge while teaching in an inner-city school. The Urban Review 36 (1), 61-79.

Silverman, D. (2000). Doing qualitative research. London: Sage.

Stake, R.E. (1995). The art of case study research. Thousand Oaks, California: Sage. Tschannen-Moran, M. \& Johnson, D. (2010). Exploring literacy teachers' selfefficacy beliefs: Potential sources at play. Teaching and Teacher Education doi:10.10.16/j.tate2010.12005

Tschannen-Moran, M. \& Woolfolk-Hoy, A. (2007). The differential antecedents of self-efficacy beliefs of novice and experienced teachers. Teaching and Teacher Education 23 (6), 944-956.

Tschannen-Moran, M., Woolfolk-Hoy, A. \& Hoy, W.K. (1998). Teacher efficacy: Its meaning and measure. Review of Educational Research 68, 202-248.

Ur, P. (1996). A course in language teaching. Cambridge: CUP.

Wedell, M. (2008). Developing a capacity to make "English for Everyone" worthwhile: Reconsidering outcomes and how to start achieving them. International Journal of Educational Development 28 (6), 628-639.

Wheatley, K.F. (2002). The potential benefits of teacher efficacy doubts for educational reform. Teaching and Teacher Education 18 (1), 5-22.

Wheatley, K.F. (2005). The case for reconceptualizing teacher efficacy research. Teaching and Teacher Education 21 (7), 747-766.

Wideen, M., Mayer-Smith, J. \& Moon, B. (1998). A critical analysis of the research on learning to teach: Making the case for an ecological perspective on inquiry. Review of Educational Research 68 (2), 130-178.

Wyatt, M. (2008). Growth in practical knowledge and teachers' self-efficacy during an in-service BA (TESOL) Programme. Unpublished PhD dissertation, School of Education, University of Leeds, UK.

Wyatt, M. (2009). Practical knowledge growth in communicative language teaching. TESL-EJ, 13 (2), 1-23.

Wyatt, M. (2010a). An English teacher's developing self-efficacy beliefs in using groupwork. System, 38 (4), 603-613.

Wyatt, M. (2010b). Teachers researching their own practice. ELT Journal. Advance Access first published online December 27, 2010. doi:10.1093/elt/ccq074

Wyatt, M. (2010c). One teacher's development as a reflective practitioner. Asian EFL Journal, 12 (2), 235-261.

Wyatt, M. (2011). Becoming a do-it-yourself designer of English language teaching materials. Forum: Qualitative Social Research 12 (1), Art 33, 1-38.

Wyatt, M. \& Borg, S. (2011). Development in the practical knowledge of language teachers: A comparative study of three teachers designing and using communicative tasks on an in-service BA TESOL programme in the Middle East. Innovation in Language Learning and Teaching. Advance 
Access first published online January 13, 2011. doi:

10.1080/17501229.2010.537340.

\section{Please cite as:}

Wyatt, M. (2013). Overcoming low self-efficacy beliefs in teaching English to young learners. International Journal of Qualitative Studies in Education 26 (2), 238-255.

http://www.tandfonline.com/doi/abs/10.1080/09518398.2011.605082 